\title{
Article \\ Changes in Parent and Child Skin Carotenoids, Weight, and Dietary Behaviors over Parental Weight Management
}

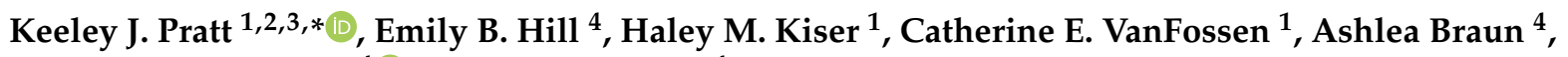 \\ Christopher A. Taylor ${ }^{4}(\mathbb{D})$ and Colleen Spees ${ }^{4}$ \\ 1 Human Development and Family Science Program, Department of Human Sciences, \\ College of Education and Human Ecology, The Ohio State University, Columbus, OH 43210, USA; \\ kiser.105@osu.edu (H.M.K.); cav79@drexel.edu (C.E.V.) \\ 2 The Ohio State Wexner Medical Center, Department of Surgery, Columbus, OH 43210, USA \\ 3 Department of Pediatrics, The Ohio State University, Columbus, OH 43210, USA \\ 4 Divison of Medical Dietetics, School of Health and Rehabilitation Sciences, \\ The Ohio State University College of Medicine, Columbus, OH 43210, USA; hill.1224@osu.edu (E.B.H.); \\ braun.165@osu.edu (A.B.); chris.taylor@osumc.edu (C.A.T.); colleen.spees@osumc.edu (C.S.) \\ * Correspondence: pratt.192@osu.edu; Tel.: +1-614-247-7883
}

Citation: Pratt, K.J.; Hill, E.B.; Kiser, H.M.; VanFossen, C.E.; Braun, A.; Taylor, C.A.; Spees, C. Changes in Parent and Child Skin Carotenoids, Weight, and Dietary Behaviors over Parental Weight Management. Nutrients 2021, 13, 2227. https:// doi.org/10.3390/nu13072227

Academic Editor: Dariusz Nowak

Received: 13 June 2021

Accepted: 27 June 2021

Published: 29 June 2021

Publisher's Note: MDPI stays neutral with regard to jurisdictional claims in published maps and institutional affiliations.

Copyright: (c) 2021 by the authors. Licensee MDPI, Basel, Switzerland. This article is an open access article distributed under the terms and conditions of the Creative Commons Attribution (CC BY) license (https:// creativecommons.org/licenses/by/ $4.0 /)$.

\begin{abstract}
The objective was to determine changes in parent-child (ages 7-18) dyad skin carotenoids spanning parental participation in a medical weight management program (WMP), and associations with parent BMI, child BMIz, fruit/vegetable intake, and family meals and patterns. (2) The study design was a longitudinal dyadic observational study with assessment at WMP initiation, mid-point (3-months), and conclusion (6-months). Twenty-three dyads initiated the study, 16 provided assessments at 3 months, and 11 at program conclusion. Associations between parent and child carotenoids (dependent variables) and parent BMI, child BMIz, increases in fruit/vegetable intake, and family meals and patterns were analyzed using Pearson's correlations and independent samples t-tests. Repeated measures ANOVA assessed changes in weight status and carotenoids. (3) Parents experienced significant declines in BMI and skin carotenoid levels over 6 months. Parent and child carotenoids were correlated at each assessment. At initiation, parent BMI and carotenoids were inversely correlated, child carotenoids were associated with increased family meals, and never consuming an evening fast food or restaurant meal were associated with increased parent and child carotenoids. (4) Results demonstrate skin carotenoids are strongly correlated within dyads and may be associated with lower parental BMI and positive family meal practices.
\end{abstract}

Keywords: skin carotenoids; parent-child; weight management; fruit and vegetable intake

\section{Introduction}

Adult obesity rates have increased over the past three decades [1,2], with half of all United States (US) adults pursuing some form of weight loss, often through medical weight management programs (WMPs) [3,4]. Given that parental obesity is the strongest risk factor for childhood obesity, these children are three-times more likely to develop obesity and future comorbidities extending into adulthood, as well as a shortened life expectancy [5-12]. Yet, we know very little about how parental participation in adult medical WMPs affects children's dietary behaviors [13]. Despite convincing evidence that parental participation in children's medical WMPs has positive effects on both child and parent behaviors and weight [14-17], there is a paucity of data on whether these same trends emerge when parents are the identified patient in these programs, and the child is not the focus. This is an important limitation with significant implications given that $50 \%$ of US adults are attempting weight loss many with children living with them who are at risk of obesity. Thus, understanding the influence of parental participation in medical WMPs on children's dietary behaviors is essential information needed before targeted 
interventions can be designed to reach a subgroup of parent-child dyads for which there are currently no tested interventions, and for children at high risk of having obesity.

Prior research conducted with children of parents in adult medical WMPs is predominately cross-sectional [13,18-21], retrospective [22,23], and isolated to parent-only perspectives $[13,18,20]$. Prospective assessments of dyads' objectively measured dietary behaviors are needed to determine short- and long-term effects of parental participation on children. Given that fruit and vegetable intake is part of a healthy diet and is a target in WMPs, finding accurate and feasible ways to track fruit and vegetable intake over WMP is necessary. However, obtaining parent and child objective measures of diet is time- and resource-intensive. One innovative, non-invasive way is through validated resonance Raman spectroscopy to measure carotenoid status in skin as a biomarker of fruit/vegetable intake $[24,25]$. Carotenoids are phytochemicals present in many fruits and vegetables that are distributed in human tissues after consumption. Assessment of carotenoid status has been validated for use as an indicator of dietary intake [26]. Objective measures of skin carotenoids consistently demonstrate moderate to strong correlations with total serum or plasma carotenoids, and are positively associated with intake of fruits and vegetables as assessed by food frequency questionnaires and automated multiple-pass 24-h daily recalls among children $\geq 5$ years-old [26-29]. This method accounts for greater accuracy in reporting, especially from children, who often provide subjective reports for dietary intake [26-29].

The objective of the study was to determine changes in parent and child fruit and vegetable intake via skin carotenoids and changes in weight (BMI, BMIz) over parental participation in an adult outpatient medical WMP, and associations between parent and child carotenoids and changes in weight, reported fruit and vegetable intake, and family meal frequency and patterns. It was hypothesized that: (1) parents experience significant decreases in BMI and increases in skin carotenoids; (2) parent and child skin carotenoids are correlated at each visit; (3) higher skin carotenoids in parents and children are associated with lower parent BMI and child BMIz at each visit; (4) higher parent and child skin carotenoids are associated with parent and child reports of increased fruit and vegetable intake at each visit; (5) more frequent family meals are associated with higher parent and child skin carotenoids at each visit; and (6) more frequent fast food, delivery, and restau$\mathrm{rant} /$ carry out consumption are associated with lower parent and child skin carotenoids at each visit.

\section{Materials and Methods}

\subsection{Study Design and Participants}

The study was a part of a larger study about the effects on children from parental participation in an adult medical WMP. The single group, longitudinal design utilized objective and survey assessments from WMP initiation, 3-months (mid-program), and 6-months (program end). Recruitment took place at parents' WMP orientation from November 2018 to March 2020, in which every eligible parent-child dyad was invited to participate. Details about the WMP at The Ohio State University Comprehensive Center for Weight Management, Metabolic and Bariatric Surgery have been described previously [30,31]. In short, the 6-month program includes nutrition, exercise, and behavioral components delivered through group educational and support classes and individual consultations with registered dietitians, behavioral health providers, and exercise physiologists. As part of the nutrition education, fruit and vegetable intake is encouraged throughout classes and consultations. There is an initial wellness orientation, in which patients have their resting metabolic rate tested and a fitness evaluation to assist in formulating individualized meal and exercise plans, respectively. Weight, dietary, and exercise journals are reviewed weekly with a post-program fitness evaluation.

Inclusion criteria comprised: parent enrolled in the WMP, child aged 7-18 years old living in the home $\geq 4$ days per week with the parent, no parent or child history of bariatric surgeries, no life-threatening comorbidities, and free of conditions that would 
prevent engagement in physical activity. The child age range of 7-18 was selected due to appropriateness of child self-report measures. If multiple children met inclusion criteria, parents were encouraged to select their youngest child. Parents who indicated interest in participation in this study at their wellness orientation were provided contact information to schedule with their child, in which consent/assent were obtained and dyads were enrolled.

\subsection{Procedures}

Parents and children had measurements of height, weight, and skin carotenoids taken, and completed a research packet that contained the measures described below the week the parent began the WMP, 3 months into the program (the half-way point), and at 6 months upon program conclusion. Parents and children had assessments completed at the University Hospital where the WMP is located. There were several exceptions when after school scheduling became challenging, where children had their measures and assessments completed with a member of the research team traveling to their home. Children were offered support from a member of the research team if they needed assistance with completing the measures. Parents and children each received a $\$ 20$ retail gift card for participation at each assessment. All subjects provided informed consent before participating in the study. The study received Institutional Review Board approval.

\subsection{Measures}

Skin carotenoids were measured by trained research staff from parents and children using a Pharmanex NuSkin BioPhotonic S3 Scanner (NuSkin Enterprises, Provo, UT, USA). This scanner uses resonance Raman spectroscopy to estimate skin carotenoids and is correlated with fruit and vegetable intake [32,33]. Parents and children completed three consecutive readings on the palm of the hand. The average of the three readings was used at each time point.

Parent and child weight status was calculated based on measured height and weight using a wall-mounted stadiometer and a scale [34]. Parent BMI was calculated, and using child date of birth, child BMI, child BMI percentile, and child BMI z-score (BMIz) were calculated, and weight status categories were determined. Child BMI percentile is used to account for changes in body composition as children age and based on sex, using age and sex specific percentiles for BMI rather than raw BMI which is used for adults. Child BMI $\mathrm{z}$-score is a measure of BMI adjusted for child age and sex on a standard growth chart, and is the standard way to measure changes for children of diverse weight status (i.e., under, healthy, overweight, obese).

Increases in fruit and vegetable intake was self-reported from parents and children using one question from Project EAT [35]: "Have you increased your fruit and vegetable intake in order to lose weight or to keep from gaining weight in the past 30 days?" Dichotomous response options include yes or no. Project EAT questions have been pilot tested and have a test-retest agreement of $88 \%$ for healthy behaviors, including the question used in this study [35].

Family meal practices were assessed from parents using four questions from the Project EAT survey [35]: "During the past 7 days, how many times did all, or most of your family living in your home eat dinner or supper together?" "During the past 7 days was a family evening meal purchased from a fast-food restaurant and eaten at the restaurant or at home?" "... was an evening meal delivered to your home?" " ... was a family evening meal picked up as takeout food?" These questions have been published with good reliability [36,37]. Questions were answered on a Likert scale: Never (0), 1-2, 3-4, 5-6, and 7 times per week. Researchers have scored the questions in different ways, using the individual family meals practices primarily as a categorical variable or dichotomizing responses per week [38-40]. For our analysis, and based on the distribution of participant responses in which there was distribution across the Likert options, "eating dinner or supper together" was dichotomized into "1-4 times per week" and "more than 4 times." The other questions about evening meals being purchased from "fast food restaurants," 
"food delivery," and "food carry out" were dichotomized into "never" and "at least one time per week" since there was limited variance in participant responses across the Likert options. These questions have good reliability $[35,37]$.

\subsection{Analysis}

Initial analysis included descriptive and bi-variate statistics. Descriptives were conducted for all variables of interest: parent and child skin carotenoids, parent BMI, child BMIz, parent and child reports of increased fruit/vegetable intake, parent reports of family meals. To test hypotheses 1 , repeated measures ANOVA was conducted using a mixed multilevel modeling approach to estimate values using Restricted Maximum Likelihood (REML), which is the ideal estimation method for missing values accounting for smaller sample sizes [41]. There were four models conducted with primary parent and child outcome variables in the time effect models including (1) parent fruit and vegetable intake via skin carotenoids, (2) child fruit and vegetable intake via skin carotenoids, (3) parent BMI, and (4) child BMIz. The models incorporated data from all three-assessment points to determine the time effects. Because of the small sample size and attrition, fixed factors and covariates were not included in the models. To test hypotheses 2-3, Pearson's correlations were run between child and parent skin carotenoids and BMI/BMIz at each time point (i.e., baseline, 3-month, 6-month). To test hypotheses 4-6, independent samples t-tests were conducted with each independent categorical variable (parent and child increased fruit/vegetable intake, family evening meal together, fast food, delivery, and carry-out) and dependent variable (parent and child skin carotenoids and BMI/BMIz) at each of the three assessment time points. Analysis was conducted using SPSS version 27 (IBM Corp., Armonk, NY, USA). Significance was set at $p<0.05$.

\section{Results}

\subsection{Sample and Demographics}

There were 53 parents with children meeting inclusion criteria invited to participate in the study. Twenty-three (43.3\%) dyads provided consent/assent and completed the first assessment the week the parent started the medical WMP. Thirty dyads did not provide consent due to not returning initial contact, lack of interest from child, or time constraints. At the 3-month (mid-program) assessment, 16 dyads completed the assessment and skin carotenoids. At the 6-month (end of program assessment), 11 dyads completed the assessment and skin carotenoids. There were no significant demographic differences between those that continued in the study and those that dropped out. Of those that dropped out of the study at 3-months, 2 dropped out of the WMP, 4 did not want to continue in the study ( 3 no response, 1 perceived child as uninterested), and due to COVID19 restrictions 1 could not have their skin carotenoids obtained. At 6-months, 2 did not want to continue in the study (no response, stated no time), 1 dropped out of the WMP, and due to COVID-19 restrictions 2 could not have their skin carotenoids obtained.

Parent and child demographics are provided in Table 1. Parents were an average age of 43 and identified as predominately female $(78 \%)$, White $(74 \%)$, non-Hispanic $(100 \%)$, married $(70 \%)$, with class II or III obesity $(87 \%)$, and with at least a Bachelor's degree $(87 \%)$. On average, parents had two children living in the home. Children were an average age of 12 and were equally split in sex (52\% female). The majority of children identified as White $(65 \%)$, non-Hispanic (83\%), and were divided between a healthy weight $(52 \%)$ and overweight/obese weight status ( $48 \%$ ).

\subsection{Descriptive Statistics}

The descriptive statistics for all variables at each time point are provided in Table 2. Parents had very high reports of increased fruit/vegetable intake at program initiation, 3 months, and 6 months $(96 \%, 94 \%, 82 \%)$; while children had more modest reports at these time points $(35 \%, 50 \%, 36 \%)$. Over half $(57 \%)$ of parents reported eating family dinner/supper together more $\geq 4$ times per week at program initiation, which decreased 
slightly at 3 months (44\%) and increased at 6 months (73\%). Parents' reports of eating evening meals that were fast food $(70 \%, 69 \%, 73 \%)$, delivered $(52 \%, 44 \%, 64 \%)$, or at a restaurant or take out $(48 \%, 50 \%, 55 \%)$ remained largely unchanged from program initiation through 6 months. There were no statistically significant differences between the measures in Table 2 over the three visits.

Table 1. Parent and Child Demographics $(\mathrm{N}=23)$ [\%(n) or Mean $\pm \mathrm{SD}]$.

\begin{tabular}{|c|c|c|c|}
\hline \multicolumn{2}{|c|}{ Parent } & \multicolumn{2}{|c|}{ Child } \\
\hline \multicolumn{2}{|c|}{ Female } & \multicolumn{2}{|c|}{ Female } \\
\hline Yes & $78.3(18)$ & Yes & $52.2(12)$ \\
\hline \multicolumn{2}{|c|}{ Race } & \multicolumn{2}{|c|}{ Race } \\
\hline White & $73.9(17)$ & White & $65.2(15)$ \\
\hline $\begin{array}{c}\text { African } \\
\text { American/Black }\end{array}$ & $17.4(4)$ & $\begin{array}{c}\text { African } \\
\text { American/Black }\end{array}$ & $17.4(4)$ \\
\hline Asian & $8.7(2)$ & Multiracial & $8.7(2)$ \\
\hline \multirow{2}{*}{\multicolumn{2}{|c|}{ Hispanic }} & Other & $8.7(2)$ \\
\hline & & \multicolumn{2}{|c|}{ Ethnicity } \\
\hline Yes & 0 & Yes & $17.4(4)$ \\
\hline Age (years) & $43.4 \pm 5.74$ & Age (years) & $12.3 \pm 3.27$ \\
\hline \multicolumn{2}{|c|}{ Weight Status } & BMI & $23.2 \pm 6.51$ \\
\hline Class I Obesity & $13.0(3)$ & BMI Percentile & $73.0 \pm 27.2$ \\
\hline Class II Obesity & $34.8(8)$ & Wei & \\
\hline Class III Obesity & $52.2(12)$ & Healthy Weight & $52.2(12)$ \\
\hline \multicolumn{2}{|c|}{ Education } & Overweight & $17.4(4)$ \\
\hline $\begin{array}{l}\text { High School } \\
\text { Graduate }\end{array}$ & $4.35(1)$ & Obese & $30.4(7)$ \\
\hline Associate Degree & $8.70(2)$ & & \\
\hline Bachelor's Degree & $69.6(16)$ & & \\
\hline$\geq$ Master's Degree & $17.4(4)$ & & \\
\hline \multicolumn{4}{|c|}{ Household } \\
\hline \multicolumn{2}{|c|}{ Annual Household Income } & \multicolumn{2}{|c|}{ Parental Relationship Status } \\
\hline$\$ 40,000-59,999$ & $17.4(4)$ & Married & $69.6(16)$ \\
\hline$\$ 60,000-99,000$ & $34.8(8)$ & Divorced & $17.4(4)$ \\
\hline$\$ 100,000+$ & $47.8(11)$ & Single & $8.70(2)$ \\
\hline Number of Children & $2.00 \pm 1.13$ & & \\
\hline
\end{tabular}

Table 2. Parent and Child Average Scores at Baseline, 3 months, and 6 months.

\begin{tabular}{|c|c|c|c|c|c|}
\hline & $\begin{array}{c}\text { Baseline } \\
(n=23)\end{array}$ & $\begin{array}{l}3 \text { Months } \\
(n=16)\end{array}$ & $\begin{array}{l}6 \text { Months } \\
(n=11)\end{array}$ & $\begin{array}{c}F(\mathrm{df}) \text { or } \\
x^{2}(\mathrm{df}, \mathrm{N})\end{array}$ & $p$ Value \\
\hline Parent carotenoids (RRS) & $26,699 \pm 10,823$ & $28,715 \pm 12,496$ & $24,595 \pm 9355$ & $0.455(2,47)$ & 0.637 \\
\hline Child carotenoids (RRS) & $28,234 \pm 12,752$ & $29,901.65 \pm 14,338$ & $30,637 \pm 13,336$ & $0.134(2,27)$ & 0.875 \\
\hline Parent BMI $\left(\mathrm{kg} / \mathrm{m}^{2}\right)$ & $43.7 \pm 8.68$ & $42.9 \pm 9.13$ & $41.9 \pm 8.53$ & $0.449(2,47)$ & 0.641 \\
\hline Child BMIz & $0.97 \pm 1.18$ & $0.93 \pm 1.18$ & $0.83 \pm 1.26$ & $0.361(2,47)$ & 0.699 \\
\hline $\begin{array}{l}\text { Parent increased fruit and } \\
\text { vegetable intake (\% yes) }\end{array}$ & $22(95.7 \%)$ & $15(93.8 \%)$ & $9(81.8 \%)$ & $2.03(2,50)$ & 0.362 \\
\hline $\begin{array}{l}\text { Child increased fruit and } \\
\text { vegetable intake (\% yes) }\end{array}$ & $8(34.8 \%)$ & $8(50.0 \%)$ & $4(36.4 \%)$ & $0.988(2,50)$ & 0.610 \\
\hline $\begin{array}{l}\text { Family dinner/supper } \\
(\%>4 \text { times per week })\end{array}$ & $13(56.5 \%)$ & $7(43.8 \%)$ & $8(72.7 \%)$ & $2.23(2,50)$ & 0.329 \\
\hline $\begin{array}{l}\text { Evening meal fast-food } \\
\text { (\% at least } 1 \text { per week) }\end{array}$ & $16(69.6 \%)$ & $11(68.8 \%)$ & $8(72.7 \%)$ & $0.053(2,50)$ & 0.974 \\
\hline $\begin{array}{l}\text { Evening meal delivery } \\
\text { (\% at least } 1 \text { per week) }\end{array}$ & $12(52.2 \%)$ & $7(43.8 \%)$ & $7(63.6 \%)$ & $1.03(2,50)$ & 0.597 \\
\hline $\begin{array}{c}\text { Evening meal restaurant or } \\
\text { takeout } \\
(\% \text { at least } 1 \text { per week })\end{array}$ & $11(47.8 \%)$ & $8(50.0 \%)$ & $6(54.6 \%)$ & $0.134(2,50)$ & 0.935 \\
\hline
\end{tabular}




\subsection{Hypotheses}

Hypothesis 1 was partially supported in which parents experienced significant declines in BMI $[F(2,25.9)=6.9, p=0.004]$ with a small effect size $\left(\eta^{2}=0.019\right)$ over 6 months (see Table 3). However, parents experienced significant decreases in skin carotenoids over six months $[F(2,25.9)=4.34, p=0.024]$ with a small $\left(\eta^{2}=0.019\right)$ effect size. There were no significant time effects for child BMIz or child skin carotenoids, though there was a small effect size for child BMIz $\left(\eta^{2}=0.015\right)$.

Table 3. Results of Repeated Measures ANOVA for Child and Parent Skin Carotenoid and BMI/BMIz.

\begin{tabular}{lcccccc}
\hline & \multicolumn{3}{c}{ Child-Reports } & \multicolumn{3}{c}{ Parent-Reports } \\
\hline & $\mathrm{df}$ & $\mathrm{F}$ & $\eta^{2}$ & $\mathrm{df}$ & $\mathrm{F}$ & $\eta^{2}$ \\
\hline $\begin{array}{c}\text { Skin } \\
\begin{array}{c}\text { Carotenoid } \\
\text { BMIz and } \\
\text { BMI }\end{array}\end{array}$ & $2,27.2$ & 0.60 & 0.006 & $2,25.9$ & $4.34 *$ & 0.019 \\
$* p<0.05, * * p<0.01$. Eta-squared $\eta^{2}=0.01$ small effect; 0.06 = medium effect; 0.14 = large effect.
\end{tabular}

Hypothesis 2 was partially supported in which parent and child skin carotenoids were positively correlated at each time point [program initiation: $\mathrm{r}(21)=0.65, p<0.001 ; 3$-month: $\mathrm{r}(14)=0.50, p=0.05$; and 6-month: $\mathrm{r}(11)=0.70, p=0.02]$.

Hypothesis 3 was partially supported, in which parent BMI was inversely correlated with parent skin carotenoids at program initiation only, $\mathrm{r}(21)=-0.44, p=0.03$. Although not statistically significant, for both parents and children, lower BMI/BMIz was associated with higher skin carotenoids at each time point (see Table S1).

Hypothesis 4 was not supported, in which there were no significant differences in child skin carotenoids between those with and without reported increases in fruit/vegetable consumption at program initiation (see Table 4). Although not statistically significant, children who reported increased fruit/vegetable consumption had higher skin carotenoids at each time point. We could not assess for differences between groups based on parent responses due to the high number of parents who reported increased fruit/vegetable consumption (96\%).

Hypothesis 5 was partially supported, in which child skin carotenoids at program initiation were higher for those participating in a greater number of family dinners (3-7 per week) (see Table 4). Although not significant, children and parents with a greater number of family dinners per week (more than 4 times) had higher skin carotenoids at each time point.

Hypothesis 6 was also partially supported, in which never consuming a weekly evening fast food meal was significantly associated with higher child and parent skin carotenoids at program initiation (see Table 4). Additionally, never eating an evening weekly meal at/or carry out from a restaurant was significantly associated with higher child skin carotenoids at program initiation; there were no significant differences in skin carotenoids based on restaurant meal consumption for parents or based on delivery of meals for either parents or children. 
Table 4. Independent t-tests Based on Child Fruit and Vegetable Intake, Family Dinner, and Evening Meals.

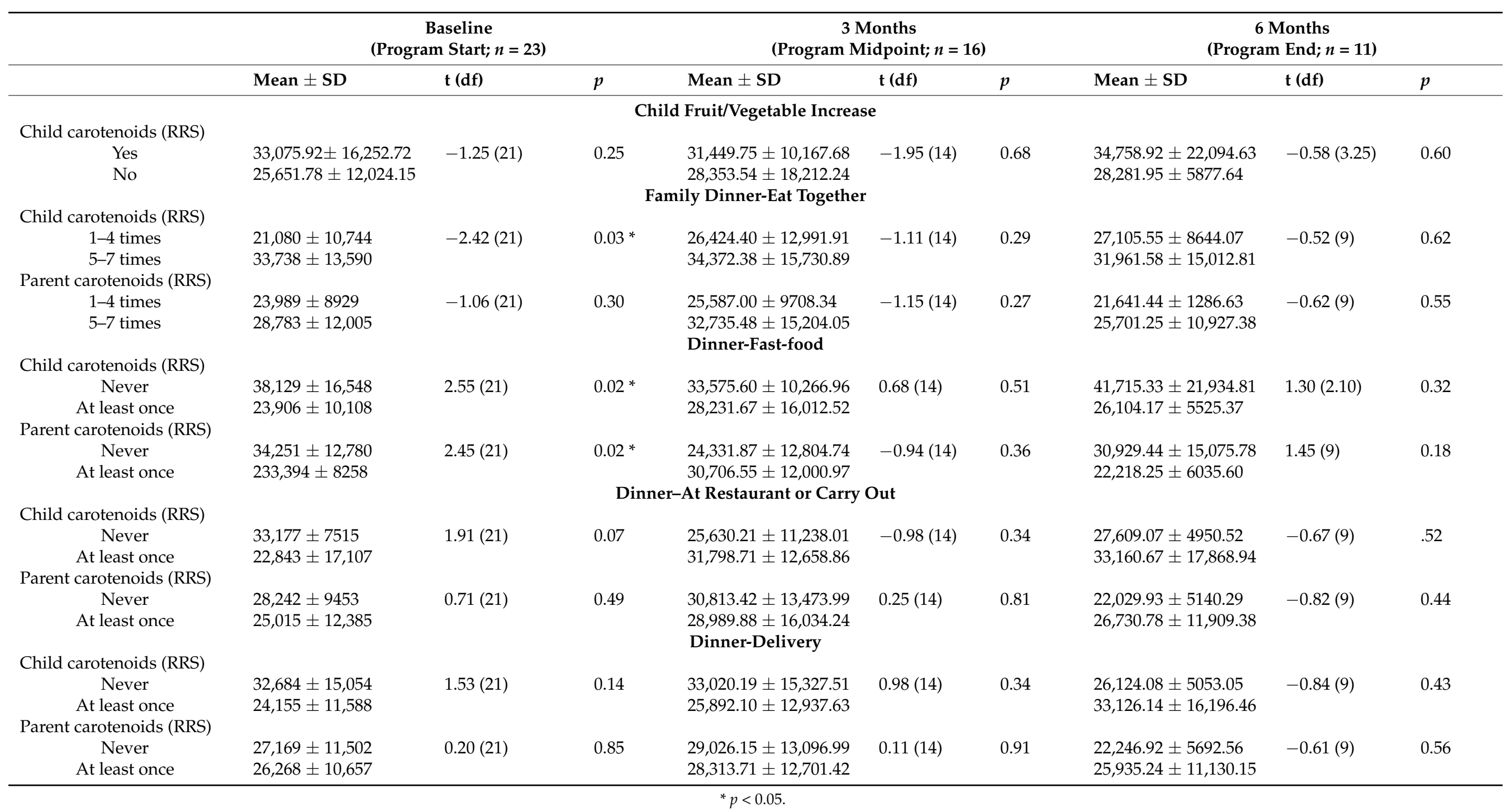




\section{Discussion}

The prospective, longitudinal design of this study allows for novel insight into parent and child changes in skin carotenoids and weight during parental participation in an adult medical WMP. Importantly, this is the first study to examine the relationship between parental participation in a WMP and objective indicators of fruit and vegetable consumption in parent-child dyads. These results build upon our previous work with parents in WMPs, and demonstrate parent and child dietary behaviors, including intakes of fruits and vegetables, are positively correlated [20]. Results also showed parental weight loss as a result of the WMP, and decreases in parental skin carotenoid levels. This provides preliminary evidence of how parental participation in WMPs affects children's dietary behaviors, and identifies a need for future investigation into sustained effects for both parents and children.

Despite parental weight loss, in contrast to expectations, we observed decreases in parent skin carotenoids over the course of WMP participation. However, nearly all parents in the study reported increases in fruit and vegetable intakes at each time point, including initiation. This suggests parents may have increased consumption of fruits and vegetables in an effort to lose weight prior to WMP initiation, and therefore change in consumption of these foods was not a dietary strategy employed throughout WMP participation. Parents may have focused instead on other weight management tactics, such as portion control or energy restriction which were not assessed in this study. As a result, the observed decrease in skin carotenoids may be related to an overall reduction in intakes as part of a goal to lower energy intake. It is also plausible this strategy led to a marked decrease in consumption of energy-dense, fat-containing foods, which are necessary for the absorption and distribution of lipid-soluble carotenoids [42]. The absence of significant change in child skin carotenoids throughout parental participation in WMP may also be explained by these factors, as parent focus on reductions in total energy intake, rather than increases in fruit and vegetable consumption, may not have led to differences in the home environment related to fruit and vegetable availability and meal composition and, therefore, would not be expected to affect fruit and vegetable intakes among children [43].

Relationships between skin carotenoids and family meal practices among participants in this study provide preliminary objective evidence for the impact of these behaviors on fruit and vegetable intakes within the context of parental WMPs. Increased frequency of family meals was positively correlated with child skin carotenoids at program initiation. Further, trends suggest an association between greater number of family meals and higher skin carotenoids among both children and parents for all time points throughout WMP participation. This indicates these meals serve as an important source of fruits and vegetables for children and parents. This observation is supported by previous literature, which has demonstrated positive relationships between family meal frequency and consumption of fruits and vegetables as well as associations with greater overall diet quality [44]. Our findings suggest fruits and vegetables are regularly consumed as part of family meals, even if relationships between skin carotenoids and increases in consumption of fruits and vegetables as part of the parental WMP were not identified.

Higher skin carotenoids were associated with lower frequency of consumption of meals prepared away from home, with significant inverse relationships identified for parents and children for fast food consumption and for children with restaurant or carry out meals at WMP initiation. These results suggest meals purchased outside the home are lower in fruits and vegetables than those prepared within the home. Previous literature also demonstrated this relationship, with away from home meals associated with poorer diet quality and lower fruit and vegetable intakes among dyads [45]. The lack of a significant relationship between skin carotenoids and meals away from home at 3- and 6-months, may indicate improvements in dietary behaviors as a result of strategies learned through parental participation in WMP.

Though this study has many strengths, including longitudinal data collection, a wellestablished adult WMP, enrollment of parent-child dyads, and objective indicators of 
fruit and vegetable consumption and height/weight, it is not without limitations. As a single-arm study, the lack of a control group limits the ability to determine the causal effect of the WMP on outcomes. Further, the small sample size, attrition, and homogeneity of participants as well as the use of a convenience sample may limit generalizability to other populations participating in adult weight management settings. The way that fruit and vegetable consumption was measured included combined increases in "fruit and vegetable" intake, and did not include the preparation of these foods (i.e., raw, processed, etc.). Bioavailability of carotenoids varies based upon the food matrix, processing conditions, preparation, and several other factors, lack of information on these details in this study impedes the ability to fully elucidate mechanisms that may have impacted changes in skin carotenoids over the course of the WMP, and thus results should be interpreted with caution [46]. Finally, future work would benefit from including assessments of 24-h food recalls or food frequency questionnaires to confer with parental and child skin carotenoids.

Supplementary Materials: The following are available online at https:/ / www.mdpi.com/article/ 10.3390/nu13072227/s1, Table S1: Correlation Matrix between Child and Parent Weight Status and Skin Carotenoids at Baseline, 3-months, and 6-months.

Author Contributions: Conceptualization, K.J.P., C.A.T. and C.S.; methodology, K.J.P., E.B.H., H.M.K., C.E.V. and A.B.; formal analysis, K.J.P., H.M.K. and C.E.V.; writing-original draft preparation/review and editing, K.J.P., E.B.H., H.M.K., C.E.V., A.B., C.A.T. and S.C; supervision, K.J.P. and C.S.; project administration, K.J.P. and C.S.; funding acquisition, K.J.P. All authors have read and agreed to the published version of the manuscript.

Funding: Salaries and research support provided by state and federal funds appropriated to The Ohio State University, Ohio Agriculture Research and Development Center; OARDC SEEDS Grant \#OHOA1634. This work was supported by Award Number Grant TL1TR002735 from the National Center for Advancing Translational Sciences. The content is solely the responsibility of the authors and does not necessarily represent the official views of the National Center for Advancing Translational Sciences or the National Institutes of Health.

Institutional Review Board Statement: The study was conducted according to the guidelines of the Declaration of Helsinki, and approved by the Institutional Review Board of The Ohio State University (2018H0308 and 9 January 2018).

Informed Consent Statement: Informed consent was obtained from all subjects involved in the study.

Conflicts of Interest: The authors declare no conflict of interest.

\section{References}

1. Flegal, K.M.; Kruszon-Moran, D.; Carroll, M.D.; Fryar, C.D.; Ogden, C.L. Trends in obesity among adults in the United States, 2005 to 2014. JAMA 2016, 315, 2284-2291. [CrossRef] [PubMed]

2. Ogden, C.L.; Carroll, M.D.; Fryar, C.D.; Flegal, K.M. Prevalence of Obesity Among Adults and Youth: United States, 2011-2014; NCHS Data Brief, No 219; National Center for Health Statistics: Hyattsville, MD, USA, 2015.

3. Snook, K.R.; Hansen, A.R.; Duke, C.H.; Finch, K.C.; Hackney, A.A.; Zhang, J. Change in percentages of adults with overweight or obesity trying to lose weight, 1988-2014. JAMA 2017, 317, 971. [CrossRef] [PubMed]

4. Martin, C.B.; Herrick, K.A.; Sarafrazi, N.; Ogden, C.L. Attempts to Lose Weight Among Adults in the United States, 2013-2016; NCHS Data Brief; NCHS: Hyattsville, MD, USA, 2018.

5. Agras, W.S.; Hammer, L.D.; McNicholas, F.; Kraemer, H.C. Risk factors for childhood overweight: A prospective study from birth to 9.5 years. J. Pediatr. 2004, 145, 20-25. [CrossRef] [PubMed]

6. Jasik, C.B.; King, E.C.; Rhodes, E.; Sweeney, B.; Mietus-Snyder, M.; Grow, H.M.; Harris, J.M.; Lostocco, L.; Estrada, E.; Boyle, K.; et al. Characteristics of youth presenting for weight management: Retrospective national data from the POWER study group. Child. Obes. 2015, 11, 630-637. [CrossRef] [PubMed]

7. Crossman, A.; Anne Sullivan, D.; Benin, M. The family environment and American adolescents' risk of obesity as young adults. Soc. Sci. Med. 2006, 63, 2255-2267. [CrossRef]

8. Franks, P.; Hanson, R.; Knowler, W.; Sievers, M.L.; Bennett, P.H.; Looker, H.C. Childhood obesity, other cardiovascular risk factors, and premature death. N. Engl. J. Med. 2010, 362, 485-493. [CrossRef] [PubMed]

9. Must, A.; Spadano, J.; Coakley, E.H.; Field, A.E.; Colditz, G.; Dietz, W.H. The disease burden associated with overweight and obesity. JAMA 1999, 282, 1523-1529. [CrossRef] [PubMed] 
10. The, N.S.; Suchindran, C.; North, K.E.; Popkin, B.M.; Gordon-Larsen, P. Association of adolescent obesity with risk of severe obesity in adulthood. JAMA 2010, 304, 2042-2047. [CrossRef]

11. Skinner, A.C.; Perrin, E.M.; Moss, L.A.; Skelton, J.A. Cardiometabolic risks and severity of obesity in children and young adults. N. Engl. J. Med. 2015, 373, 1307-1317. [CrossRef]

12. Reilly, J.J.; Kelly, J. Long-term impact of overweight and obesity in childhood and adolescence on morbidity and premature mortality in adulthood: Systematic review. Int. J. Obes. 2011, 35, 891-898. [CrossRef]

13. Pratt, K.; Ferriby, M.; Brown, C.; Noria, S.; Needleman, B.; Skelton, J.A. Adult weight management patients' perceptions of family dynamics and weight status. Clin. Obes. 2019, 9, e12326. [CrossRef]

14. Epstein, L.H.; Paluch, R.A.; Roemmich, J.N.; Beecher, M.D. Family-based obesity treatment, then and now: Twenty-five years of pediatric obesity treatment. Health Psychol. 2007, 26, 381-391. [CrossRef] [PubMed]

15. Kang Sim, D.E.; Strong, D.R.; Manzano, M.A.; Rhee, K.E.; Boutelle, K.N. Evaluation of dyadic changes of parent-child weight loss patterns during a family-based behavioral treatment for obesity. Pediatr. Obes. 2020, 15, e12622. [CrossRef]

16. Pona, A.A.; Carlson, J.A.; Shook, R.P.; Dreyer Gillette, M.L.; Davis, A.M. Maternal BMI Change Linked to Child Activity Change in Family-Based Behavioral Interventions for Pediatric Weight Management. Child. Obes. 2019, 15, 371-378. [CrossRef]

17. Wrotniak, B.H.; Epstein, L.H.; Paluch, R.A.; Roemmich, J.N. Parent weight change as a predictor of child weight change in family-based behavioral obesity treatment. Arch. Pediatr. Adolesc. Med. 2004, 158, 342-347. [CrossRef] [PubMed]

18. Pratt, K.J.; Ferriby, M.; Noria, S.; Skelton, J.; Taylor, C.; Needleman, B. Perceived child weight status, family structure and functioning, and support for health behaviors in a sample of bariatric surgery patients. Fam. Syst. Health 2018, 38, 300-309. [CrossRef] [PubMed]

19. Sellberg, F.; Ghaderi, A.; Willmer, M.; Tynelius, P.; Berglind, D. Change in children's self-concept, body-esteem, and eating attitudes before and 4 years after maternal RYGB. Obes. Surg. 2018, 28, 3276-3283. [CrossRef]

20. Brown, C.L.; Pratt, K.; Martin, S.; Hulshult, H.; Skelton, J.A. Weight control practices in children of parents participating in weight management programs. Child. Obes. 2019, 15, 451-458. [CrossRef] [PubMed]

21. Willmer, M.; Berglind, D.; Tynelius, P.; Ghaderi, A.; Naslund, E.; Rasmussen, F. Changes in eating behaviour and food choices in families where the mother undergoes gastric bypass surgery for obesity. Eur. J. Clin. Nutr. 2016, 70, 35-40. [CrossRef]

22. Watowicz, R.P.; Taylor, C.A.; Eneli, I.U. Lifestyle behaviors of obese children following parental weight loss surgery. Obes. Surg. 2013, 23, 173-178. [CrossRef]

23. Woodard, G.A.; Encarnacion, B.; Peraza, J.; Hernandez-Boussard, T.; Morton, J. Halo effect for bariatric surgery. Arch. Surg. 2011, 146, 1185. [CrossRef] [PubMed]

24. Aguilar, S.S.; Wengreen, H.J.; Lefevre, M.; Madden, G.J.; Gast, J. Skin carotenoids: A biomarker of fruit and vegetable intake in children. J. Acad. Nutr. Diet. 2014, 114, 1174-1180. [CrossRef] [PubMed]

25. Radtke, M.D.; Pitts, S.J.; Jahns, L.; Firnhaber, G.C.; Loofbourrow, B.M.; Zeng, A.; E Scherr, R. Criterion-related validity of spectroscopy-based skin carotenoid measurements as a proxy for fruit and vegetable intake: A systematic review. Adv. Nutr. 2020, 11, 1282-1299. [CrossRef]

26. Institute of Medicine (US) Panel on Dietary Antioxidants and Related Compounds. Dietary Reference Intakes for Vitamin $C$, Vitamin E, Selenium, and Carotenoids; $\beta$-Carotene and Other Carotenoids; National Academies Press (US): Washington, DC, USA, 2000. Available online: https://www.ncbi.nlm.nih.gov/books/NBK225469/ (accessed on 1 January 2020).

27. Nguyen, L.M.; Scherr, R.E.; Linnell, J.D.; Ermakov, I.V.; Gellermann, W.; Jahns, L.; Keen, C.L.; Miyamoto, S.; Steinberg, F.M.; Young, H.M.; et al. Evaluating the relationship between plasma and skin carotenoids and reported dietary intake in elementary school children to assess fruit and vegetable intake. Arch. Biochem. Biophys. 2015, 572, 73-80. [CrossRef] [PubMed]

28. Spees, C.K.; Hill, E.B.; Grainger, E.M.; Buell, J.L.; White, S.E.; Kleinhenz, M.D.; Clinton, S.K. Feasibility, preliminary efficacy, and lessons learned from a garden-based lifestyle intervention for cancer survivors. Cancer Control. 2016, 23, 302-310. [CrossRef]

29. Mayne, S.T.; Cartmel, B.; Scarmo, S.; Jahns, L.; Ermakov, I.V.; Gellermann, W. Resonance raman spectroscopic evaluation of skin carotenoids as a biomarker of carotenoid status for human studies. Arch. Biochem. Biophys. 2013, 539, 163-170. [CrossRef]

30. Pratt, K.; Jalilvand, A.; Needleman, B.; Urse, K.; Ferriby, M.; Noria, S. Postoperative outcomes based on patient participation in a pre-surgery education and weight management program. Surg. Obes. Relat. Dis. 2018, 14, 1714-1723. [CrossRef] [PubMed]

31. Pratt, K.J.; VanFossen, C.; Kiser, H.; Riley, W.; Colleen, S.A.T.C.; Ihuoma, E.; Sabrena, N. Dyadic reports of weight control practices, sedentary behaviors, and family functioning and communication between adult weight management patients and their children. Obes. Sci. Pract. 2021, 7, 326-334. [CrossRef]

32. Ermakov, I.V.; Sharifzadeh, M.; Ermakova, M.; Gellermann, W. Resonance raman detection of carotenoid antioxidants in living human tissue. J. Biomed. Opt. 2005, 10, 064028. [CrossRef]

33. Mayne, S.T.; Cartmel, B.; Scarmo, S.; Lin, H.; Leffell, D.J.; Welch, E.; Ermakov, I.; Bhosale, P.; Bernstein, P.S.; Gellermann, W. Noninvasive assessment of dermal carotenoids as a biomarker of fruit and vegetable intake. Am. J. Clin. Nutr. 2010, 92, 794-800. [CrossRef]

34. Fryar, C.D.; Gu, Q.; Ogden, C.L. Anthropometric Reference Data for Children and Adults: United States, 2007-2010; CDC: Atlanta, GA, USA, 2012.

35. Neumark-Sztainer, D.; Wall, M.M.; Larson, N.; Story, M.; Fulkerson, J.A.; Eisenberg, M.E.; Hannan, P.J. Secular trends in weight status and weight-related attitudes and behaviors in adolescents from 1999 to 2010. Prev. Med. 2012, 54, 77-81. [CrossRef] 
36. Svetkey, L.P.; Ard, J.D.; Stevens, V.J.; Loria, C.M.; Young, D.Y.; Hollis, J.F.; Appel, L.J.; Brantley, P.J.; Kennedy, B.M.; Kumanyika, S.K.; et al. Predictors of long-term weight loss in adults with modest initial weight loss, by sex and race. Obesity 2012, 20, 1820-1828. [CrossRef] [PubMed]

37. Fulkerson, J.A.; Story, M.; Neumark-Sztainer, D.; Rydell, S. Family meals. Perceptions of benefits and challenges among parents of 8- to 10-year-old children. J. Am. Diet. Assoc. 2008, 108, 706-709. [CrossRef] [PubMed]

38. Berge, J.; Wall, M.; Larson, N.; Loth, K. Family functioning: Associations with weight status, eating behaviors, and physical activity in adolescents. J. Adolesc. Health 2013, 52, 351-357. [CrossRef] [PubMed]

39. Berge, J.M.; MacLehose, R.F.; Loth, K.A.; Eisenberg, M.E.; Fulkerson, J.A.; Neumark-Sztainer, D. Family meals. Associations with weight and eating behaviors among mothers and fathers. Appetite 2011, 58, 1128-1135. [CrossRef] [PubMed]

40. Newman, S.L.; Tumin, R.; Andridge, R.; Anderson, S.E. Family meal frequency and association with household food availability in United States multi-person households: National health and nutrition examination survey 2007-2010. PLoS ONE 2015, 10, e0144330. [CrossRef] [PubMed]

41. IBM Corp. Released 2017. IBM SPSS Statistics for Windows; Version 25.0; IBM Corp.: Armonk, NY, USA, 2017.

42. Moran, N.E.; Mohn, E.S.; Hason, N.; Erdman, J.W., Jr.; Johnson, E.J. Intrinsic and extrinsic factors impacting absorption, metabolism, and health effects of dietary carotenoids. Adv. Nutr. 2018, 9, 465-492. [CrossRef]

43. Rolls, B.J.; Ello-Martin, J.A.; Tohill, B.C. What can intervention studies tell us about the relationship between fruit and vegetable consumption and weight management? Nutr. Rev. 2004, 62, 1-17. [CrossRef]

44. Robson, S.M.; McCullough, M.B.; Rex, S.; Munafò, M.R.; Taylor, G. Family meal frequency, diet, and family functioning: A systematic review with meta-analyses. J. Nutr. Educ. Behav. 2020, 52, 553-564. [CrossRef]

45. Lachat, C.; Nago, E.; Verstraeten, R.; Roberfroid, D.; Van Camp, J.; Kolsteren, P. Eating out of home and its association with dietary intake: A systematic review of the evidence. Obes. Rev. 2012, 13, 329-346. [CrossRef]

46. Bohn, T.; McDougall, G.J.; Alegría, A.; Alminger, M.; Arrigoni, E.; Aura, A.; Brito, C.; Cilla, A.; el, S.N.; Karakaya, S.; et al. Mind the gap-deficits in our knowledge of aspects impacting the bioavailability of phytochemicals and their metabolites-a position paper focusing on carotenoids and polyphenols. Mol. Nutr. Food Res. 2015, 59, 1307-1323. [CrossRef] [PubMed] 